\title{
Estimation of Physiological Cost Index as an Energy Expenditure Index using MacGregor's Equation
}

\author{
Binaya SJB Rana, ${ }^{1}$ Matiram Pun' \\ 'Department of Clinical Physiology, Maharajgunj Medical Campus, Institute of Medicine, Tribhuvan University.
}

\section{ABSTRACT}

Background: Physical activity and energy expenditure can be quantified by measuring heart rate, oxygen uptake and respiratory quotient. The Physiological Cost Index (PCI) proposed by MacGregor is a simple and straightforward method to estimate the energy expenditure index. Here, we aim to estimate the energy expenditure among young Asian population using MacGregor's equation.

Methods: A total of 50 young randomly selected healthy females performed $50 \mathrm{~m}, 100 \mathrm{~m}$ and $150 \mathrm{~m}$ walking test at their self-selected preferred speed. The physiological cost index values for $100 \mathrm{~m}$ walk at speeds slower and faster than the preferred speed were also obtained. The physiological cost index during exercise was calculated using MacGregor's equation considering heart rate and speed of walking over the varying distances.

Results: The PCI values on three different distances are consistent during self selected preferred speed. The PCI estimation on second and third tests for all three distances walked consistently reproducible. However for each distance walked, the first test the PCI was significantly higher than the second and third test values. The PCI values increased significantly when subjects walked either slower $(p=0.02)$ or faster $(p=0.001)$ than their normal preferred speed.

Conclusion: The physiological cost index values were similar for varying distances walks. The PCI was the least at the preferred speed of walking and increased when the subjects either walked slower or faster than the preferred speed. The first estimation was higher than subsequent estimations.

Keywords: energy expenditure index; exercise; physiological cost index.

\section{INTRODUCTION}

Energy expenditure during physical activities during various activities for example, running, hiking, walking depends upon specific patterns of speed of the subject, inclination of the surface, distance elapsed. These physical activities are directly related with the wellbeing, happiness and healthy lifestyle. ${ }^{1,2}$ All of the above activities require certain amounts of energy and there are various methods of estimating it. The primary and fundamental physiological parameters for the estimation of energy expenditure during such activities are heart rate, oxygen uptake and respiratory quotient. ${ }^{3}$ These parameters can now be accurately measured in digital format during exercise especially in bicycle ergometer and treadmill test. In advanced labs, we can monitor electrocardiogram, heart rate, blood

Correspondence: Dr. Binaya S.J.B. Rana, Department of Clinical Physiology, Maharaiguni Medical Campus, Institute of Medicine, Tribhuvan University. Nepal. Email: matiram@gmail.com, Phone: +977. 9851178182/ +91-9605657941. 
Rana et al. Estimation of Physiological Cost Index as an Energy Expenditure Index using MacGregor's Equation: A Cross-Sectional ...

pressure in beat-by-beat basis, inspired-expired gases in breath-by-breath basis and blood oxygen saturation. This is of course among individuals who can perform exercise in these set-up i.e. able-bodied subjects. It has been demonstrated that the heart rate and oxygen uptake have a linear relationship with the sub maximal work loads. ${ }^{4,5}$ However, these setups are not available everywhere especially developing countries or remote resource limiting settings. There are other low-cost but acceptable method of estimating energy consumption. One of them is to monitor the heart rate response to a particular physical activity and estimate of energy expenditure.$^{6,7}$ Heart rate is more easily measured than oxygen uptake and it has been shown in adults to be an accurate and convenient method of estimating of energy expenditure. ${ }^{7}$ The walking method, heart rate monitoring and energy expenditure estimation has been validated among both normal children and children with cerebral palsy children while walking. ${ }^{7}$

One of the validated methods of estimating of energy expenditure index considering heart rate and walking speed (over a certain meter distance) was put forth by McGregor. ${ }^{8}$ MacGregor coined this method as Physiological Cost Index (PCl) which is the ratio of heart rate per meter walked expressed as beats/meter. Literatures mention that heart rate was first measured at different walking speeds by Braune and Fischer in 1895. ${ }^{6}$ Heart rate per se is an important measurement of physical exertion ${ }^{8}$ although it is influenced by many factors for example emotional overlay and stress. Another important source of variance with heart rate response is related to the fitness (i.e.athletes) of the individual. ${ }^{8}$ Hence, for this reason, MacGregor ${ }^{8}$ developed the concept of an empirical index: the physiological cost index which is defined as change in heart rate (difference between rest and while walking in beats/ min) divided by walking speed (meters/min).

MacGregor ${ }^{8}$ used the preferred speed of walking among female normal subjects and Rose et al ${ }^{9}$ also used heart rate and walking speed to calculate an energy expenditure index (EEI) i.e. the ratio of heart rate per meter walked. The EEI calculated by Rose et al ${ }^{9}$ using walking heart rate minus the resting heart rate divided by the walking speed was expressed as beats/meter, similar to the units of physiological cost index (PCI) of MacGregor.Here we attempt to estimate physiological cost of walking with a simplified technique with simply measuring the pulse rate by palpatory method with the help of a stop watch and walking speed. This simple approach to $\mathrm{PCl}$ estimation has not been reported in the literature to our knowledge. The study was also aimed to check the reliability and reproducibility of the results over different distances with different speeds MacGregor's equation. ${ }^{8}$

\section{METHODS}

The study was conducted at the Locomotor Evaluation and Gait Analysis Laboratory (LEG Lab) of the Department of Orthopaedics in Kasturba Medical College and Hospital, Manipal (January to December, 2000). The LEG Lab spans over 16.66 meters on the floor equipped with dedicated computer programmed to calculate $\mathrm{PCl}$ when resting heart rate, final heart rate, distance walked and the time taken for walking were fed. The computer was also used to assist in the timing of the subject's walk. A total of 50 young female nursing students (17-21 years)from the Department of Physiology, Shiridi Sai Baba Cancer Hospital and College of Nursing, Manipal; were recruited for the study. With preliminary screening, they were excluded if they had fever, physical disability, cardiac or pulmonary disease, using medications and had history of recent surgery.

\section{Experimental Protocol}

For the first session of the day of experimental visit, the subjects were invited the LEG Lab in a group of 4-5 subjects. After 10 minutes of familiarization, the instructions were explained about the experimental protocols. The walks at self-selected preferred speed, slow speed and fast speed were demonstrated on the marked rectangular walkway. The $\mathrm{PCl}$ values were obtained for 50, 100 and 150m distance walks at the self-selected, preferred speed. Then $\mathrm{PCl}$ values were obtained for slow-speed and fast-speed walks for $100 \mathrm{~m}$ distance. The same subjects were then called back for two more sessions on different days (intervals between sessions ranging from 1 to 15 days) and the same walking tests were repeated in exactly the same manner for each subject.

\section{Recording Pulse Rate}

After lab familiarization and walking experiment orientation, the resting pulse rate of the subject was obtained by counting the radial pulse by palpatory method. The subject was then taken to the starting point and asked to walk along the marked walkway at his/her self-selected preferred speed for three rounds to complete a distance of $50 \mathrm{~m}$. A verbal command "start" was given at the beginning and "stop" at the end of the walk by the investigator. Simultaneously the walk was timed by the computer. Immediately at the end of the specified walk, the subject's radial pulse was recorded from the same wrist by palpatory method.

\section{Calculation of Physiological Cost Index using MacGregor's equation}

Energy expenditure index based on heart rate and walking speed has been termed Physiological Cost 
Rana et al. Estimation of Physiological Cost Index as an Energy Expenditure Index using MacGregor's Equation: A Cross-Sectional ...

Index $(\mathrm{PCl})$ by MacGregor. ${ }^{8} \mathrm{PCl}$ is the ratio of heart rate per meter walked and it is calculated by the following formula:

$\mathrm{PCl}=\frac{\text { Walking heart rate }(\text { beats } / \mathrm{min})-\text { Resting }}{\text { Speed of walking }(\text { meters } / \mathrm{min})}$

The $\mathrm{PCl}$ is expressed as beats/meter.

The data obtained are expressed as mean \pm standard deviation (SD) and were analysed using standard statistical package (SPSS Version 11). The data was subjected to paired ' $\mathrm{t}$ ' tests (Student ' $\mathrm{t}$ ' test) $\mathrm{PCl}$ variation with different distances at self-selected preferred speed, to check the reproducibility of $\mathrm{PCl}$ as a measure of energy consumption during walking at selfselected preferred speed, and to see the correlation of $\mathrm{PCl}$ with slow speed and fast speed $100 \mathrm{~m}$ walks.

\section{RESULTS}

A total of 50 young, Indian females aged 17 to 21 years (mean 19.56 years) with mean body mass index (BMI) of 19 performed the walking tests on 3 different occasions for 3 different distances $150 \mathrm{~m}, 100 \mathrm{~m}$ and
$150 \mathrm{~m})$ at self-selected preferred speed. The $\mathrm{PCl}$ values were also obtained for $100 \mathrm{~m}$ distance walk on every occasion for slow speed and fast speed.

\section{The effect of varying distances on Physiological Cost} Index

The $\mathrm{PCl}$ values on three different distances are remarkably consistent with self selected preferred speed (Table 1). The comparison of the $\mathrm{PCl}$ values between vary distances ( $\mathrm{PCl}$ of 50 vs $\mathrm{PCl} 100 \mathrm{~m}, \mathrm{PCl}$ of $50 \mathrm{~m}$ vs $\mathrm{PCl} 150 \mathrm{~m}$ and $\mathrm{PCl}$ of $100 \mathrm{~m}$ vs $\mathrm{PCl}$ of $150 \mathrm{~m}$ ) did not result any statistically difference (Table 2 ).

\begin{tabular}{|c|c|c|}
\hline Distance & NUMBER OF & $\mathrm{PCl} \pm \mathrm{SD}$ \\
\hline Walked & SUBJECTS & \\
\hline $50 \mathrm{~m}$ & 50 & $0.207 \pm 0.03$ \\
\hline $100 \mathrm{~m}$ & 50 & $0.208 \pm 0.03$ \\
\hline $150 m$ & 50 & $0.211 \pm 0.03$ \\
\hline
\end{tabular}

Table 2. The comparison of $\mathrm{PCl}$ values on the varying distances at the self selected preferred speed of walking.

\begin{tabular}{|ccrrrr|}
\hline Mean \pm SD & Mean \pm SD & Differences (Mean \pm SD) & Paired't' test & $p$-Value \\
$\mathrm{PCl}(50) 0.21 \pm 0.03$ & $\mathrm{PCl}(100) 0.21 \pm 0.03$ & $-0.001 \pm 0.01$ & -0.59 & 0.561 \\
$\mathrm{PCl}(50) 0.21 \pm 0.03$ & $\mathrm{PCl}(150) 0.21 \pm 0.03$ & $-0.004 \pm 0.02$ & -1.64 & 0.108 \\
$\mathrm{PCl}(100) 0.21 \pm 0.03$ & $\mathrm{PCl}(150) 0.21 \pm 0.03$ & $-0.003 \pm 0.01$ & -1.74 & 0.087 \\
\hline
\end{tabular}

Note: The numbers within brackets after $\mathrm{PCl}$ indicate the distance walked.

The reproducibility of the Physiological Cost Index (PCI) estimation

\begin{tabular}{|c|c|c|c|c|}
\hline \multirow{2}{*}{$\begin{array}{l}\text { Distance } \\
\text { Walked }\end{array}$} & \multicolumn{3}{|c|}{ Mean PCI Values ( \pm SD) } & \multirow[b]{2}{*}{ Significance } \\
\hline & Test I & Test II & Test III & \\
\hline $50 \mathrm{~m}$ & $\begin{array}{l}0.23 \pm \\
0.03\end{array}$ & $\begin{array}{l}0.21 \pm \\
0.03\end{array}$ & $\begin{array}{l}0.21 \pm \\
0.03\end{array}$ & $\begin{array}{l}\text { Test I } \mathrm{PCI} \text { value was significantly higher than Test II and } \\
\text { III values, } \mathrm{p}<0.001 \text {. }\end{array}$ \\
\hline $100 \mathrm{~m}$ & $\begin{array}{l}0.23 \pm \\
0.04\end{array}$ & $\begin{array}{l}0.21 \\
\pm 0.03\end{array}$ & $\begin{array}{l}0.21 \pm \\
0.03\end{array}$ & $\begin{array}{l}\text { Test I PCI value was significantly higher than Test II and } \\
\text { III values, } p<0.001 \text {. }\end{array}$ \\
\hline $150 \mathrm{~m}$ & $\begin{array}{l}0.24 \pm \\
0.04\end{array}$ & $\begin{array}{l}0.21 \pm \\
0.03\end{array}$ & $\begin{array}{l}0.21 \pm \\
0.03\end{array}$ & $\begin{array}{l}\text { Test I PCI value was significantly higher than Test II and } \\
\text { III values, } p<0.001 \text {. }\end{array}$ \\
\hline Significance & NS & NS & NS & \\
\hline
\end{tabular}


Rana et al. Estimation of Physiological Cost Index as an Energy Expenditure Index using MacGregor's Equation: A Cross-Sectional ...

The reproducibility of estimates of $\mathrm{PCl}$ was excellent between the second and third tests for all three distances walked (Table 3). Furthermore, PCl values for each test were identical for all three distances walked (see at the bottom of Table 3 with no statistically different). However, for each distance walked, the first test value of $\mathrm{PCl}$ was significantly higher than the second and third test values of $\mathrm{PCl}$ as shown in the Table 3 .

Note: NS stands for 'No Significance'. The effect of speed of walking on Energy Expenditure

\section{Index (EEI)}

It was observed that $\mathrm{PCl}$ value for slow speed was significantly higher from the $\mathrm{PCl}$ value for self-selected preferred speed ( $p=0.02$, Table 4). It was observed that $\mathrm{PCl}$ value for the fast speed was significantly higher from the $\mathrm{PCl}$ value for self-selected preferred speed ( $p=0.001$, Table 5). Therefore, Table 4 and Table 5 showed that the $\mathrm{PCl}$ values increased significantly when subjects walked either slower or faster than their normal preferred speed.

Table 4. The comparison of $\mathrm{PCl}$ values at $100 \mathrm{~m}$ in a preferred speed with $\mathrm{PCl}$ value of $100 \mathrm{~m}$ at slow speed.

\begin{tabular}{lllll}
\hline Mean PCI 100m for preferred speed & $\begin{array}{l}\text { Mean PCI 100m for slow } \\
\text { speed }\end{array}$ & $\begin{array}{l}\text { Difference (mean } \pm \\
\text { SD) }\end{array}$ & $\begin{array}{l}\text { Paired 't' } \\
\text { p-value }\end{array}$ \\
$0.21 \pm 0.03$ & $0.22 \pm 0.04$ & $-.02 \pm .04$ & -3.32 & .002
\end{tabular}

Table 5. The comparison of $\mathrm{PCl}$ values of $100 \mathrm{~m}$ at preferred speed with the $\mathrm{PCl}$ value of $100 \mathrm{~m}$ at fast speed.

Mean PCl $100 \mathrm{~m}$ for preferred speed

(E)

$0.21 \pm 0.03$
Mean $\mathrm{PCl} 100 \mathrm{~m}$ for fast speed

$0.33 \pm 0.05$

\section{Difference (mean}

\pm SD)

$-.12 \pm .05$
Paired 't' p-value

$-16.81$
.001

\section{DISCUSSION}

The physiological cost index values on three different distances $(50 \mathrm{~m}, 100 \mathrm{~m}$ and $150 \mathrm{~m}$ ) are consistent with self selected preferred speed among 50 young, Indian females with a mean age of 19.56 years and mean body mass index of 19 . There is no statistically difference between the $\mathrm{PCl}$ values over varying distances $150 \mathrm{~m}$ versus $100 \mathrm{~m}, 50 \mathrm{~m}$ versus $150 \mathrm{~m}$ and $100 \mathrm{~m}$ versus $150 \mathrm{~m})$. The results were consistent between the second and third tests for all three distances walked and also the $\mathrm{PCl}$ values for each test were identical for all three distances walked. However, for each distance walked, the first test value of $\mathrm{PCl}$ was significantly higher than the second and third test. On the varying speed over $100 \mathrm{~m}$ distance, the $\mathrm{PCl}$ values for both slowerand faster speeds were significantly higher from the $\mathrm{PCl}$ value for self-selected preferred speed.

Typically, the rate of oxygen consumption is an index of energy expenditure during any physical activity like walking. ${ }^{3,5}$ It is evident from the scientific literature that the heart rate and oxygen consumption are linearly related under sub-maximal work conditions in normal individuals, including healthy children.4,5,10 A similar relationship is found in handicapped patients ${ }^{4,11}$ as well. MacGregor devised more practical approach for the objective assessment of walking efficiency or physiological cost of normal as well as disabled individuals ${ }^{8}$ as a physiological cost index which employed the parameters of heart rate and self-selected preferred speed in contrast to conventional estimation of oxygen uptake. The 'preferred gait' concept emerged which was readily demonstrated by the patient and yielded very reproducible performance among more challenging subjects for example with amputees and other disabled patients. MacGregor ${ }^{8}$ had actually employed a $200 \mathrm{~m}$ figure-of-eight walk path on the floor of his laboratory to obtain preferred walking speed and a radio-telemetered electrocardiogram to monitor heart rate. However, the facility is not always accessible in all the laboratories. Therefore, here it has been improvised the technique to manually record radial pulse and input the data in the computer. But recording heart rate with radial pulse is a far the most convenient method although it can be influenced by other variables during low levels of activity or when the subject is at rest. If the subject is nervous or uncomfortable, the heart rate may increase, compromising the validity of the technique. Hence, a careful and consistent recording of the pulse is mandatory in this manual method.

The $\mathrm{PCl}$ values for all three distances of $50 \mathrm{~m}, 100 \mathrm{~m}$ and $150 \mathrm{~m}$ at preferred speed were remarkably consistent. The reason for getting almost identical values may be that the group of nursing students formed a homogenous sample because all of them belonged to the same college and were familiar with hospital environment and stressful situations. Therefore, there was no statistically significant difference between $\mathrm{PCl}$ 
Rana et al. Estimation of Physiological Cost Index as an Energy Expenditure Index using MacGregor's Equation: A Cross-Sectional ...

values for varying distances of 50,100 and $150 \mathrm{~m}$. The $\mathrm{PCl}$ values for all distances during the Test I were significantly different with all the $\mathrm{PCl}$ values obtained during the Test II and Test III. This finding probably supports the view that anxiety and apprehension about the investigation exerted its maximum effect during most of the $50 \mathrm{~m}$ walking tests to which the subjects were exposed for the first time. It could be presumed that the subjects got more accustomed during the subsequent tests in the same session.

The mean $\mathrm{PCl}$ of the subjects $(0.22 \pm 0.04$ beats $/ \mathrm{m})$ for $100 \mathrm{~m}$ distance walk at slow speed (mean $57 \mathrm{~m}$ / min.) was significantly higher than the mean $\mathrm{PCl}$ value $(0.21 \pm 0.03)$ for $100 \mathrm{~m}$ distance walk at self selected preferred speed (mean $65 \mathrm{~m} / \mathrm{min}$ ), $\mathrm{p}<0.05$. This was consistent with Mac Gregor's study ${ }^{8}$ which showed that the $\mathrm{PCl}$ function had a curvilinear distribution in normal subjects as well as virtually all patients (with the possible exception of the extremely severely handicapped) with a clearly demonstrable $\mathrm{PCl}$ minimum in the middle of the individual's speed range. The minimum values found were associated with their walking speeds self-selected by the individual as being preferred. This is probably due to walking activity which seemed least demanding to the subject in the laboratory and was the most frequent speed observed in 24 hour monitoring of the unhurried subject. Rose et $\mathrm{al}^{9}$ have also reported the lowest $\mathrm{PCl}$ value and optimal energy economy occurred at the selfselected comfortable walking speeds among children and adults. In some respects it was an optimum speed of the subject. As expected, the energy consumption during fast speed (mean $78 \mathrm{~m} / \mathrm{min}$ ) was much higher $(\mathrm{PCl}=0.33 \pm 0.05$ beats $/ \mathrm{m})$ for $100 \mathrm{~m}$ distance walk as compared to preferred speed $(\mathrm{PCl}=0.21 \pm 0.03$ beats $(\mathrm{m})$. This is consistent with normal physiological response to increased physical activity. MacGregor and Rose et $\mathrm{al}^{89,12}$ have also reported that self-selected preferred speed was more economical than slow speed which is supported by the data here in this study.

In terms of age, disability and energy expenditure, there is no significant correlation between energy expenditure and age was evident ${ }^{6}$ and also it was not statistically different between the children with cerebral palsy and normal ${ }^{12}$ on heart rate and oxygen uptake. Similarly, there was no significant difference between males and females regarding oxygen uptake per $\mathrm{kg}$ in young adults and seniors during free level walking. ${ }^{6}$ The energy expenditure of free walking in men and women aged between 20 and 59 years did not have significantly different values with their age or sex. ${ }^{13}$ Although lean body mass is highly correlated with aerobic capacity, most studies show that at submaximal work loads such as walking, total body weight correlates more highly with energy expenditure than lean body mass. ${ }^{6}$ Similarly, the body height seems to have a small but consistent effect on energy expenditure while walking. It was found that short people used more oxygen to walk than tall people of the same body weight at all walking speeds. ${ }^{6}$ Here, the $\mathrm{PCl}$ values for varying distances at self selected preferred speed had no correlation with height, weight and body mass index (BMI) of the subjects. Workman and Armstrong ${ }^{6}$ report that body height has a small but consistent effect on the metabolic cost of walking (short people using more oxygen to walk than tall people of the same body weight at all walking speeds). This is because, probably because short steps are more "wasteful" than long steps. Asian population is shorter than Western population but here the study population had normally distributed height and weight. Since the test sample consisted of young female nursing students with low BMI (mean 19.31), it is possible that their body weight represented lean body mass which correlates better with body fat. Therefore no correlation was seen between $\mathrm{PCl}$ and body mass index in the present study.

The past studies have validated that EEI estimated considering heart rate and EEl calculated as oxygen uptake have been found consistent. ${ }^{12}$ The values of both indices when plotted as a function of various walking speeds and a similar curvilinear distribution were found for both indices. Therefore, the $\mathrm{PCl}$ or EEI (HR) had a direct linear relationship with oxygen uptake. Both indices were equally reliable for evaluation of energy consumption during walking. The energy cost of walking was found to be economical at comfortable walking speeds and higher at slower and faster speeds of walking. Various studies have used heart rate to estimate $\mathrm{PCl}$ and $\mathrm{EEI}$ as a reliable measure ${ }^{4,8,9,11,12,14}$ among both normal subjects and physically challenged as well as musculoskeletal disorder subjects. ${ }^{3,15-20}$ They have employed heart rate as one of the two variables, the other being walking speed, in their estimation of physiological cost index (PCI) or energy expenditure index (EEI). Here, $\mathrm{PCl}$ and $\mathrm{EEI}$ are different names for the same index. Hence, the $\mathrm{PCl}$ or EEI can be effectively as well as accurately estimated using heart rate, a standard distance (consistent) and speed. Here, it is also found that it can be performed among young Indian females with consistent results.

\section{CONCLUSION}

The physiological cost index as a measure of energy consumption during walking in a cohort of healthy young female adults was estimated among 50 normal healthy young female adults. The $\mathrm{PCl}$ was estimated recording radial pulse by palpation (as a measure of heart rate) and were made to walk in a three different distances $(50 \mathrm{~m}, 100 \mathrm{~m}$ and $150 \mathrm{~m})$ at their preferred speed on 3 different occasions. $\mathrm{PCl}$ values for $100 \mathrm{~m}$ walk at speeds slower and faster than the preferred speed were 
also obtained. The PCl estimated during walking 100 $\mathrm{m}$ at their preferred speed of ambulation was $0.21 \pm$ 0.03 beats/meter. The $\mathrm{PCl}$ values were the same for 50 meter, 100 meter and 150 meter walks. The $\mathrm{PCl}$ value was the least at the preferred speed of walking and increased when the subjects either walked slower or faster than the preferred walking speed.When repeated estimation of $\mathrm{PCl}$ was done on the same subjects, it was noted that the first estimation recorded higher values than subsequent estimations. The reproducibility of second and third recordings of $\mathrm{PCl}$ was excellent.

The study has been among young females and with relatively homogenous age, race, body mass index and physical activity relatively small sample size. The heart rate recording was done manually and it would be best should it have been with heart rate monitor or electrocardiogram monitor that usually done with. The instructions especially for slower and faster speed than their preferred speed were a bit difficult to convey and translate into experiment. Metronome with rhythmic beat of faster and slower than their own preferred speed could be used to standardize the speed. It would probably be the best to compare energy expenditure with other standard protocols for example bicycle ergometer or tread-mill test either on the same subjects or with controls.

\section{ACKNOWLEDGEMENTS}

The Department of Physiology, Kasturba Medical College and Hospital, Manipal, study participants from The Shiridi Sai Baba Cancer Hospital and College of Nursing, Manipal,The Locomotor Evaluation and Gait Analysis Laboratory (LEG Lab) of the Department of Orthopaedics in Kasturba Medical College and Hospital, Manipal.

\section{REFERENCES}

1. Fox KR. The influence of physical activity on mental well-being. Public health nutrition. 1999;2:411-8.

2. Penedo FJ, Dahn JR. Exercise and well-being: a review of mental and physical health benefits associated with physical activity. Current opinion in psychiatry. 2005;18:189-93.

3. Davies JB. Use of heart rate in assessment of orthoses. Physiotherapy. 1977;63:112-4.

4. Nene AV, Jennings SJ. Physiological cost index of paraplegic locomotion using the ORLAU ParaWalker. Paraplegia. 1992;30:246-52.

5. Waters RL, Hislop HJ, Perry J, Antonelli D. Energetics: application to the study and management of locomotor disabilities. Energy cost of normal and pathologic gait. The Orthopedic clinics of North America. 1978;9:351-6.

6. Rose J, Gamble JG. Human Walking. Second Edition ed: Baltimore: Williams and Wilkins; 1994.

7. Rose J, Gamble JG, Medeiros J, Burgos A, Haskell WL. Energy cost of walking in normal children and in those with cerebral palsy: comparison of heart rate and oxygen uptake. Journal of pediatric orthopedics. 1989;9:276-9.

8. MacGregor J. The evaluation of patient performance using long-term ambulatory monitoring technique in the domiciliary environment. Physiotherapy. 1981;67:30-3.

9. Rose J, Gamble JG, Lee J, Lee R, Haskell WL. The energy expenditure index: a method to quantitate and compare walking energy expenditure for children and adolescents. Journal of pediatric orthopedics. 1991;11:571-8.

10. Bar-On ZH, Nene AV. Relationship between heart rate and oxygen uptake in thoracic level paraplegics. Paraplegia. 1990;28:87-95.

11. Nene A. Physiological cost index of walking in able-bodied adolescents and adults. Clinical rehabilitation. 1993;7:319-26.
12. Rose J, Gamble JG, Burgos A, Medeiros J, Haskell WL. Energy expenditure index of walking for normal children and for children with cerebral palsy. Developmental medicine and child neurology. 1990;32:333-40.

13. Blessey R. Energy cost of normal walking. The Orthopedic clinics of North America. 1978;9:356-8.

14. Butler P, Engelbrecht M, Major RE, Tait JH, Stallard J, Patrick JH. Physiological cost index of walking for normal children and its use as an indicator of physical handicap. Developmental medicine and child neurology. 1984;26:607-12.

15. Steven MM, Capell HA, Sturrock RD, MacGregor J. The physiological cost of gait (PCG): a new technique for evaluating nonsteroidal anti-inflammatory drugs in rheumatoid arthritis. British journal of rheumatology. 1983;22:141-5

16. Engsberg JR, Herbert LM, Grimston SK, Fung TS, Harder JA. Relation among indices of effort and oxygen uptake in below-knee amputee and able-bodied children. Archives of physical medicine and rehabilitation. 1994;75:1335-41.

17. Stallard J, Major RE. The influence of orthosis stiffness on paraplegic ambulation and its implications for functional electrical stimulation (FES) walking systems. Prosthetics and orthotics international. 1995;19:108-14.

18. Yang L, Condie DN, Granat MH, Paul JP, Rowley DI. Effects of joint motion constraints on the gait of normal subjects and their implications on the further development of hybrid FES orthosis for paraplegic persons. Journal of biomechanics 1996;29:217-26.

19. Burridge JH, Taylor PN, Hagan SA, Wood DE, Swain ID. The effects of common peroneal stimulation on the effort and speed of walking: a randomized controlled trial with chronic hemiplegic patients. Clinical rehabilitation. 1997;11:201-10.

20. Tofts LJ, Stanley CS, Barnett TG, Logan JG. Knee joint function and the energy cost of level walking in soccer players. British journal of sports medicine. 1998;32:130-3. 